\title{
Immobilization of Coypus (Myocastor coypus) with Ketamine Hydrochloride and Xylazine Hydrochloride
}

R. F. B6,' F. Palomares, ${ }^{2}$ J. F. Beltrán, ${ }^{3}$ G. de Villafañe,' and S. Moreno, ${ }^{2}$ ' Grupo de Estudios sobre Ecología Regional, Departamento de Ciencias Biológicas, Facultad de Ciencias Exactas y Naturales, Universidad de Buenos Aires, Ciudad Universitaria, Pabellón II, (1428) Buenos Aires, Argentina: ${ }^{2}$ Estación Biológica Doñana, Consejo Superior de Investigaciones Cientificas, Apartado 1056, 41080 Sevilla, Spain; ${ }^{3}$ Caeser Kleberg Wildlife Research Institute, Texas A\&I University, Campus Box 218, Kingsville, Texas 78363, USA

ABSTRACT: A combination of $100 \mathrm{mg} / \mathrm{ml}$ of ketamine hydrochloride (Ket) and $20 \mathrm{mg} / \mathrm{ml}$ of xylazine hydrochloride (Xyl) was used to immobilize coypus (Myocastor coypus). Eight mature coypus (four males and four females) were injected intramuscularly with doses ranging from 2.33 to $6.25 \mathrm{mg} / \mathrm{kg}$ of $\mathrm{KET}$ and 0.25 to 0.86 $\mathrm{mg} / \mathrm{kg}$ of $\mathrm{Xyl}$. The mean $( \pm \mathrm{SE})$ time for induction, arousal, and recovery were $7.3 \pm 2 \mathrm{~min}$, $23.5 \pm 0.3 \mathrm{~min}$ and $46 \pm 2.5 \mathrm{~min}$, respectively. The mean $\pm \mathrm{SE}$ doses injected were $4.07 \pm 0.52$ $\mathrm{mg} / \mathrm{kg}$ Ket (range, 2.33 to $6.25 \mathrm{mg} / \mathrm{kg}$ ) and 0.5 $\pm 0.08 \mathrm{mg} / \mathrm{kg} \mathrm{Xyl}$ (range, 0.25 to $0.86 \mathrm{mg} / \mathrm{kg}$ ). No adverse responses were observed in any of the animals treated.

Key words: Coypu, Myocastor coypus, ketamine hydrochloride, xylazine hydrochloride, chemical immobilization, field study.

There are many studies regarding biology and management of the coypu (Myocastor coypus), both in nature and in captivity, mainly in countries where it has been introduced (Kinler et al., 1987), but there are few published data about the chemical immobilization of this species (Van Foreest, 1980; Jalanka and Roeken, 1990). This knowledge would be useful in field studies where animals are handled for only short periods, and then are released in the field. Xylazine (Xyl) is a sedative with analgesic and muscular relaxant effects that is frequently used combined with dissociative anesthetics such as ketamine (Ket), of short duration and ample safety margin (Greene and Thurmon, 1988). This combination usually results in smooth induction and recovery (Belant, 1991) and has been used successfully with large herbivores, carnivores, furbearers and rodent species (Szabuniewicz et al., 1978; Jessup et al., 1983; Logan et al., 1986; Belant, 1991). Our objective was to determine the effects of several combination of Xyl-Ket as a chemical immobilizer on coypus in field studies.

During July 1990 eight mature coypus were captured in a freshwater marsh in the delta of the Paraná River, $5 \mathrm{~km}$ east of Puerto Constanza, Entre Ríos, Argentina $\left(34^{\circ} 48^{\prime} \mathrm{S}, 58^{\circ} 57^{\prime} \mathrm{W}\right)$, using leghold traps (Oneida-Victor No. 2, A. Jonsson Co., Buenos Aires, Argentina). The strength of the springs was modified to reduce striking and clamping actions of the trap in order to reduce any possible damage in the animals. We studied four male and four female coypus of varying age classes that weighed from 2 to $6.1 \mathrm{~kg}$. Age and reproductive condition were estimated from body mass (Crespo, 1974). Coypus were put in net bags for transportation to the immobilization site. Immobilization was carried out with a 1-ml hand-syringe.

Each coypu was injected intramuscularly with a combination of $100 \mathrm{mg} / \mathrm{ml}$ Ket (Ketolar, Parke Davis S.A., El Prat de Lobregat, Barcelona, Spain) and $20 \mathrm{mg} /$ ml Xyl (Rompún, Instituto Bayer de Terapéutica Experimental S.A., Barcelona, Spain). If required, an additional injection of $0.75 \mathrm{mg} / \mathrm{kg} \mathrm{Ket}$ and $0.15 \mathrm{mg} / \mathrm{kg} \mathrm{Xyl}$ was used to maintain anesthesia.

The general state of anesthesia and animal activity was controlled throughout the experiment, and the times till induction, arousal and recovery were recorded. Induction time was defined as the time from injection until the animal lost consciousness. Arousal time was defined as the time between loss of responsiveness until it started to lift and move its head, and recovery time was defined as the time from injection until it could remain standing in spite of the box being moved to different positions. 
TABLE 1. Responses of eight sexually mature coypus (four males and four females) immobilized with ketamine hydrochloride and xylazine hydrochloride, Delta of the Paraná River, Argentina, July to August 1990.

\begin{tabular}{lcccc}
\hline & Median & Mean & SE & Range \\
\hline Ketamine hydrochloride $(\mathrm{mg} / \mathrm{kg})$ & 4.12 & 4.07 & 0.52 & $2.33-6.25$ \\
Xylazine hydrochloride $(\mathrm{mg} / \mathrm{kg})$ & 0.45 & 0.50 & 0.08 & $0.25-0.86$ \\
Individual weight $(\mathrm{kg})$ & 3.65 & 3.63 & 0.42 & $2.00-6.10$ \\
Induction time $(\mathrm{min})$ & 7.00 & 7.30 & 2.00 & $5.50-9.50$ \\
Arousal time $(\mathrm{min})$ & 23.0 & 23.5 & 0.31 & $23.0-25.0$ \\
Recovery time $(\mathrm{min})$ & 45.5 & 46.0 & 2.53 & $38.0-55.0$ \\
\hline
\end{tabular}

Sedated coypus received a radio collar (Biotrack Ltd., Wareham, United Kingdom) and were kept in boxes with a reed bedding (Scirpus californicus) until complete recovery. They then were released at the capture site. Due to the low temperature $(5 \mathrm{C})$, animals were kept in a sunny spot protected from the wind during the period of manipulation and recovery to reduce the risk of hypothermia.

The mean $( \pm \mathrm{SE})$ doses injected were $4.07 \pm 0.52 \mathrm{mg} / \mathrm{kg}$ Ket and $0.5 \pm 0.08$ $\mathrm{mg} / \mathrm{kg}$ Xyl. The mean ( $\pm \mathrm{SE}$ ) induction time was $7.3 \pm 2 \min (n=8)$. No evidence of adverse responses were observed in any animals. The mean $( \pm \mathrm{SE})$ arousal and recovery times were $23.5 \pm 0.3$ and $46 \pm$ $2.5 \mathrm{~min}$, respectively $(n=8)$ (Table 1 ).

Only two specimens, both sub-adult males, had to receive additional injections of Ket and Xyl. They probably were excited because they were transported together in the same net bag to the site of immobilization. However these extra doses were relatively low as compared with the total amount injected (4.5 and $4.25 \mathrm{mg}$ / $\mathrm{kg}$ Ket and 0.8 and $0.65 \mathrm{mg} / \mathrm{kg}$ of $\mathrm{Xyl}$ respectively).

Two coypus had partial immobility of one of their limbs for several minutes, perhaps due to use of leghold traps. However, leghold traps were chosen due to their greater efficiency, particularly in water sets, as compared with other live capture methods used for this species (Robicheaux and Linscombe, 1978).

The average dose of Ket used in this study $(4 \mathrm{mg} / \mathrm{kg}$ ) was similar to that used in captive coypus by Jalanka and Roeken (1990) but lower than that recommended by Van Foreest (1980). Jalanka and Roeken (1990) used $5 \mathrm{mg} / \mathrm{kg}$ Ket in 18 coypu immobilizations but replaced $\mathrm{Xyl}$ with 0.1 $\mathrm{mg} / \mathrm{kg}$ of medetomidine. Van Foreest (1980) recommended an average dose of $11 \mathrm{mg} / \mathrm{kg}$ Ket for surgical anesthesia but he considered that $5.3 \mathrm{mg} / \mathrm{kg}$ Ket and 0.42 $\mathrm{mg} / \mathrm{kg}$ Xyl were sufficient for handling and physical examination of captive coypus.

The use of Ket and $\mathrm{Xyl}$ with average doses of 4 and $0.5 \mathrm{mg} / \mathrm{kg}$, respectively, seemed to be enough to immobilize this species in the field, allowing a safe and proper manipulation, and a swift and complete recovery.

However, owing to the limited information on this species, we suggest further experiments with different dosages of Ket and $\mathrm{Xyl}$ and with other drugs, such as medetomidine, to maximize the field efficiency of immobilization, without affecting unnecessarily the health of the animals.

We thank Mr. O. Maglione for help in capturing the animals and for allowing us to carry out this experiment on his property; the owner of the San Lorenzo timber Company, Mr. A. Pulenta and his personnel, particularly J. Barros and Mr. and Mrs. Cívico, for their support during the experiments; and Mr. Jorge Merler for his collaboration in the field. This research was carried out thanks to a scientific cooperation agreement of the Ministry of Education and Science of Spain between the GESER, Dpto. Cs. Biológicas, FCEyN, 
Univ. de Buenos Aires (Argentina) and E. B. Doñana, Cons. Sup. de Invest. Científicas, Sevilla (Spain).

\section{LITERATURE CITED}

BELANT, J. L. 1991. Immobilization of fishers (Martes pennati) with ketamine hydrochloride and xylazine hydrochloride. Journal of Wildlife Diseases 27: 328-330.

Crespo, J. A. 1974. Observaciones sobre la reproducción de la nutria en estado silvestre. Primer Congreso Argentino de Producción nutriera. Santa Fe 1: 60-73.

Greene, S. A., AND J. C. Thurmon. 1988. Xylazine-A review of its pharmacology and use in veterinary medicine. Journal of Veterinary Pharmacology and Therapeutics 11: 295-313.

Jalanka, H. H., and O. Roeken. 1990. The use of medetomidine, medetomidine-ketamine combinations, and atipamezole in nondomestic mammals: A review. Journal of Zoo and Wildlife Medicine 21: 259-282.

Jessup, D. A., W. E. Clark, P. A. Gullet, and K. R. JONES. 1983. Immobilization of mule deer with ketamine and xylazine and reversal of immobilization with yohimbine. Journal of the American Veterinary Medical Association 183, 1339-1340.
KinleR, N., G. LiNSCOMBE, AND P. R. RAMSEY. 1987. Nutria. In Wild furbearer management and conservation in North America, M. Novak, J. A. Baker, M. E. Obbard and B. Mallack (eds.). Ministry of Natural Resources, Ontario, Canada, pp. 327343.

Logan, K. A., E. T. Thorne, L. L. Irwin, and R. SKINNER. 1986. Immobilizing wild mountain lions (Felis concolor) with ketamine hydrochloride and xylazine hydrochloride. Journal of Wildlife Diseases 22: 97-103.

RobicheaUX, B. L., AND G. LiNSCOMBE 1978. Effectiveness of live traps for capturing furbearers in a Louisiana coastal marsh. Proceedings of the Annual Conference of the Southeastern Association of Fish and Wildlife Agencies 32: 208-212.

Szabuniewicz, M., L. Sanchez, A. Sosa, and M. DE GOMEZ. 1978. Sedación y anestesia del chiguire (Hydrochoerus hydrochoeris, Linné). Revista de la Facultad de Ciencias veterinarias de la Universidad Central de Venezuela 8: 61-78.

VAN FOREEST, A. 1980. Use of ketamine/xylazine combination for tail amputation in nutria (Myocastor coypus). Journal of Zoo Animal Medicine 11: 19-20.

Received for publication 26 October 1992. 